\title{
Exhaled nitric oxide in paediatric asthma and cystic fibrosis
}

\author{
J O N Lundberg, S L Nordvall, E Weitzberg, H Kollberg, K Alving
}

\begin{abstract}
Nitric oxide (NO) is present in exhaled air of humans. This NO is mostly produced in the upper airways, whereas basal NO excretion in the lower airways is low. Children with Kartagener's syndrome have an almost total lack of NO in nasally derived air, whereas adult asthmatics have increased NO in orally exhaled air. NO excretion was measured in the nasal cavity and in orally exhaled air in 19 healthy children, in 36 age matched subjects with asthma, and in eight children with cystic fibrosis. NO levels in orally exhaled air were similar in controls and in children with cystic fibrosis, at 4.8 (SD 1.2) $v 5.8$ (0.8) parts per billion (ppb), but were increased in asthmatic children who were untreated or were being treated only with low doses of inhaled steroids (13.8 (2.5) ppb). Nasal NO levels were reduced by about $\mathbf{7 0 \%}$ in children with cystic fibrosis compared to controls and asthmatics. Measurements of airway NO release in different parts of the airways may be useful in non-invasive diagnosis and monitoring of inflammatory airway diseases. (Arch Dis Child 1996;75:323-326)
\end{abstract}

Keywords: Kartagener's syndrome, nitric oxide synthase, chemiluminescence.

Nitric oxide (NO) is present in exhaled air of humans. ${ }^{1}$ In healthy subjects, the major part of NO found in exhaled air is derived from the upper airways, with only a minor contribution from the lower respiratory tract and the lungs. ${ }^{2}$ Substantial NO production takes place in the epithelium of the paranasal sinuses, where an NO synthase, closely resembling the inducible NO synthase, is constitutively expressed. ${ }^{4}$ Sinus derived NO enters the nasal cavity through the sinus ostia and contributes prominently to the levels of $\mathrm{NO}$ found in nasally exhaled air. ${ }^{5}$ Normal NO concentrations found in the sinuses exceed those that are bacteriostatic to Staphylococcus aureus, ${ }^{6}$ thereby suggesting a role for NO in airway host defence. Furthermore, NO has also been shown to upregulate ciliary activity. ${ }^{7}$ Children with Kartagener's syndrome are almost totally without NO in nasally derived air. ${ }^{2}$ The reason for this is not clear but it is possible that less NO passes from the sinuses to the nasal cavity, since the sinuses are often full of mucus in patients with this disease. ${ }^{8}$ Alternatively, the lack of NO could reflect a deficient mucosal NO production.
NO has also been implicated in the pathogenesis of inflammation when produced in excess by an inducible NO synthase (iNOS). This NOS isoform may be expressed in many cell types after stimulation by certain proinflammatory cytokines or bacterial products such as lipopolysaccharide. ' For example, iNOS is found in asthmatic bronchial epithelium $^{10}$ and adult asthmatics show enhanced NO excretion in the lower airways, as indicated by increased levels of NO in orally exhaled air. ${ }^{11}$ Furthermore, greatly increased luminal NO levels have been found in the colons of patients with ulcerative colitis ${ }^{12}$ or Crohns' disease. ${ }^{13}$ Glucocorticoids are known to inhibit the expression of the iNOS, and adult asthmatics on treatment with these drugs do not differ from controls as far as exhaled NO levels are concerned. ${ }^{14}$ This suggests that iNOS expression is responsible for the raised NO levels seen in asthmatic patients who are not on steroid treatment.

We have studied NO excretion in the upper and lower airways in asthmatic children on regular treatment with different doses of inhaled steroids, as well as in children and adults with cystic fibrosis. NO concentrations were compared with those from healthy age matched controls. Parts of these results have been presented in a preliminary form. ${ }^{1516}$

\section{Methods}

SUBJECTS

Controls were 19 healthy children, 5-15 years old, without any history of allergy or respiratory tract disease.

Asthma patients were 36 children also aged 5-15 years. These children were regular attenders at the allergy clinic of St Görans Children's Hospital and were on antiasthmatic drug treatment: 12 were taking low doses (0-100 $\mu \mathrm{g}$ daily) of inhalant glucocorticoids (budesonide, Pulmicort Turbuhaler, Draco, Sweden), 16 were on moderate daily doses $(200-400 \mu \mathrm{g})$, and eight were on high daily doses $(600-800 \mu \mathrm{g})$.

During a short interview, which was a part of the examination, the severity of the children's asthma was evaluated according to the suggestions of the Swedish Paediatric Association. Exercise induced asthma was also graded arbitrarily as none, mild (two episodes per month), moderate, or severe (more than three episodes per week). Nasal stuffiness was interpreted as a sign of a perennial rhinitis.

Cystic fibrosis patients were eight children, aged 4-14 years, none of whom were on steroids, and only one was chronically colo-

Stockholm, Sweden. 
nised with Pseudomonas aeruginosa. In addition, three older patients with cystic fibrosis $(20,23$, and 27 years old) were studied. The two oldest were chronically colonised with $P$ aeruginosa and both were on inhaled steroids daily (400 and $1600 \mu \mathrm{g}$ respectively). All cystic fibrosis patients except the oldest were chronically colonised with $S$ aureus. They had all been diagnosed with cystic fibrosis on the basis of typical clinical symptoms and pathologically raised concentrations of $\mathrm{NaCl}$ in sweat (double tests).

\section{ORALLY EXHALED NO}

The subjects breathed normal tidal volumes through the mouth while wearing a nose clip. Exhaled air was extracted into Teflon tubing and NO was measured with a chemiluminescence NO/NOx analyser (CLD 700, Eco Physics, Dürnten, Switzerland, detection limit 1 part per billion, ppb) as described earlier. ${ }^{11}$ Steady state levels of NO were registered on a chart recorder.

NASALLY EXHALED NO

The subjects used a face mask and breathed normal tidal volumes through the nose with the mouth closed. Exhaled NO levels were measured as described above.

\section{DIRECT NASAL SAMPLING}

NO was also measured in air sampled directly from one nostril $(0.7 \mathrm{l} / \mathrm{min})$. A nasal olive was connected directly to the sampling tube of the $\mathrm{NO}$ analyser and introduced into one nostril. The subjects were asked to breathe through the mouth while the contralateral nostril was left open. Thus air was forced from one side of the nose to the other via the nasopharynx. Plateau levels of NO were registered on a chart recorder.

Ambient NO levels were below 3 ppb during all experiments.

\section{Results}

ORALLY EXHALED NO

Asthmatic children treated with no or low doses of topical steroids and those treated with moderately high doses showed increased NO concentrations (13.8 (SD 2.5) ppb and 9.2 (1.9) $\mathrm{ppb}$, respectively) compared to controls (4.8 (1.1) ppb) (fig 1A). Asthmatics treated with the highest doses of steroids did not differ significantly from controls (fig 1A). No difference was found between asthmatics with perennial allergic rhinitis and those without rhinitis (10.3 (1.6) ppb and 13.5 (3.5) ppb, respectively; $\mathrm{p}>0.05$ ).

Orally exhaled NO concentrations did not differ significantly between controls and children with cystic fibrosis (5.8 (0.8) ppb) (fig 2A). NO concentrations in the older cystic fibrosis patients were 2-7 ppb.

\section{NASALLY EXHALED NO}

NO values in nasally exhaled air did not differ significantly between controls and asthmatics, at 21 (9.1) v $27(2.6) \mathrm{ppb}, \mathrm{p}>0.05$, but a tendency toward higher concentrations was seen in patients who used no or low doses of
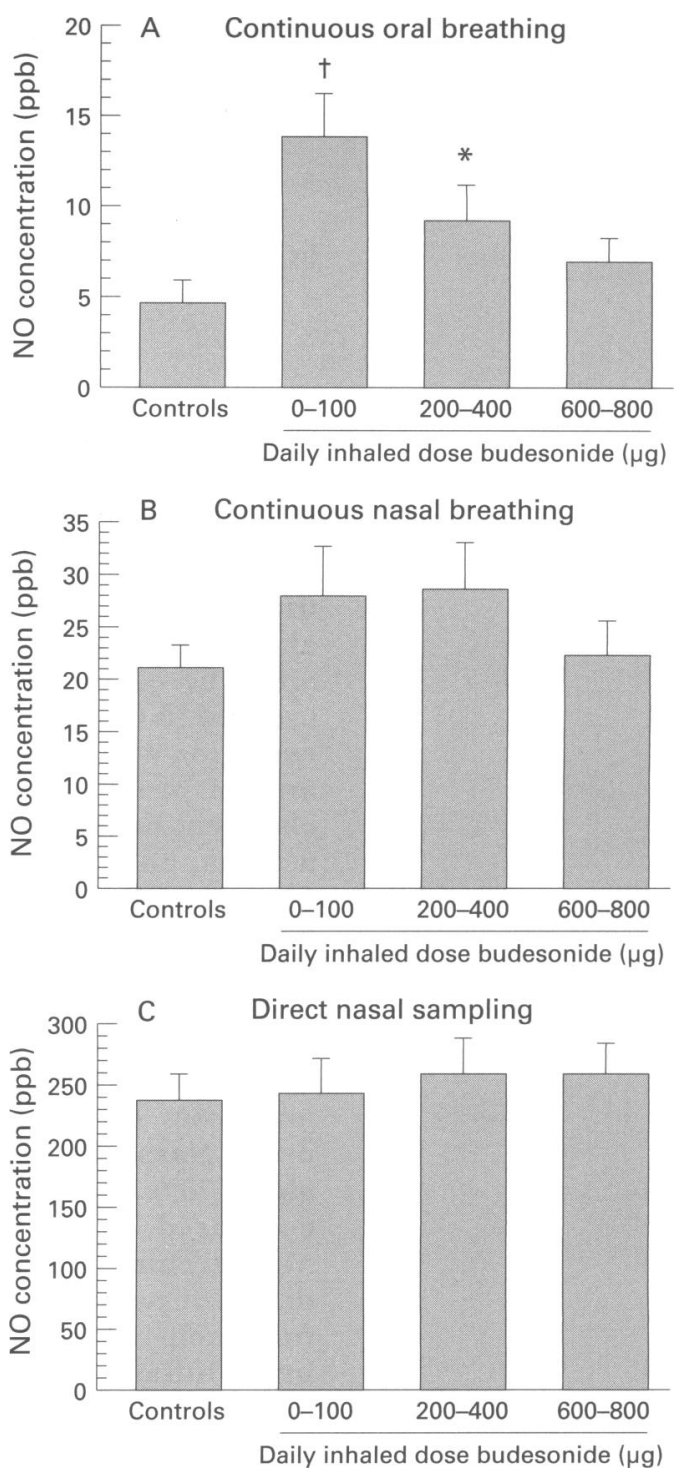

Figure 1 NO concentrations in orally or nasally exhaled air or in air sampled directly from one nostril in healthy children and in age matched asthmatic children treated with inhaled glucocorticoids. ${ }^{\star} p<0.05$ and $t p<0.001 v$ controls (Kruskal-Wallis with Dunn's multiple comparisons).

inhaled steroids (fig 1B). Concomitant allergic rhinitis did not influence nasally exhaled NO concentrations in the asthmatic children: 26 (3.6) $\mathrm{ppb}$ in asthmatics without rhinitis, $\mathrm{n}=$ 16 , and 29 (4) ppb in the patients with rhinitis, $\mathrm{n}=20, \mathrm{p}>0.05$. In contrast, children with cystic fibrosis had lower nasally exhaled NO concentrations than controls (fig 2B). NO concentrations in the three older cystic fibrosis patients were similar to those seen in children with cystic fibrosis (9-15 ppb).

DIRECT NASAL SAMPLING

Nasal NO concentrations were similar in controls and asthmatics, at 239 (20) v 254 (17) ppb, but were approximately $70 \%$ lower in the cystic fibrosis children (72 (18) ppb, p<0.001, fig $2 \mathrm{C}$. The NO concentrations in asthmatics treated with low doses of steroids and those treated with higher doses were similar (fig 1C). NO levels did not differ between asthmatics with rhinitis and those without, at 252 (20) $v$ 256 (26) ppb, p>0.05. In the older cystic fibro- 

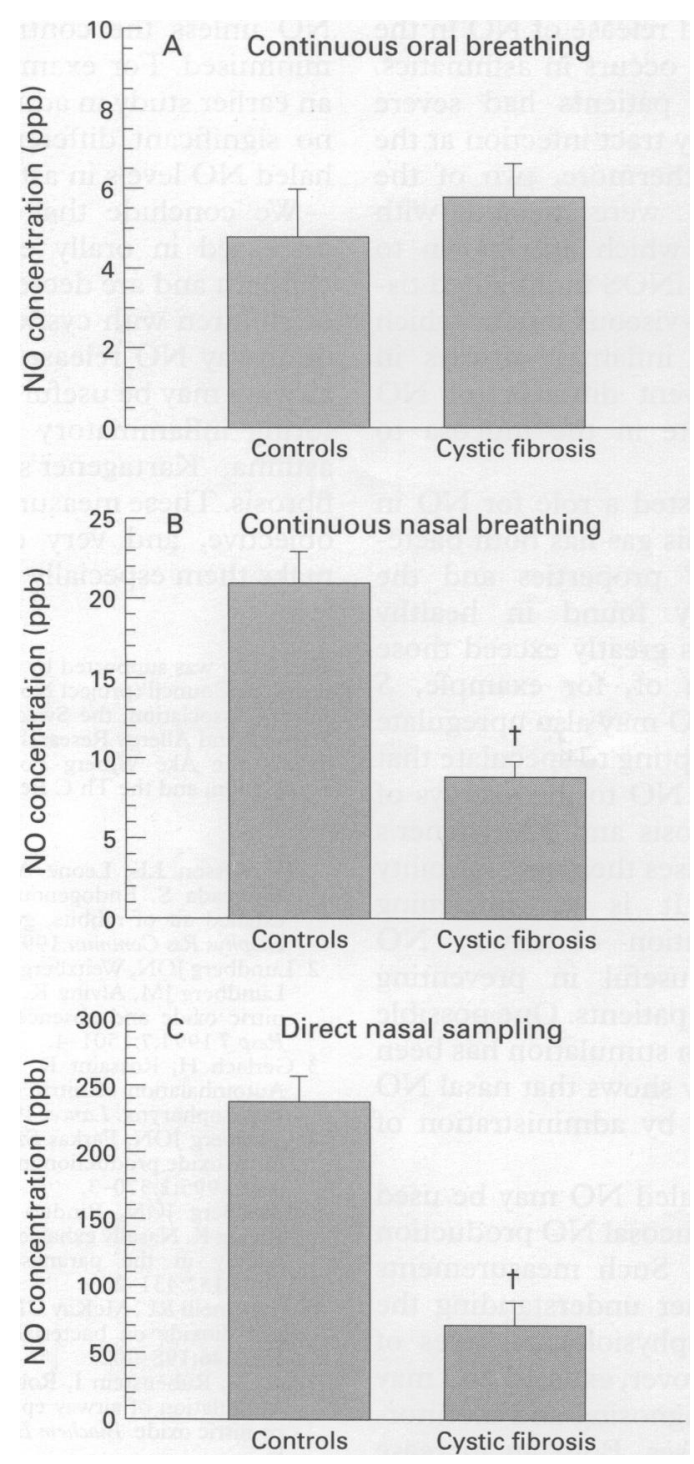

Figure 2 NO concentrations in orally or nasally exhaled air or in air sampled directly from one nostril in healthy air or in air sampled directly from one nostril in healthy
children and in children with cystic fibrosis. $t p<0.001 v$ controls (Mann-Whitney $U$ test).

sis patients nasal NO concentrations were 40-105 ppb.

Age, sex, severity of asthma, and presence of exercise induced asthma did not correlate with NO levels for the three different NO measurement techniques used in this study (not shown).

\section{Discussion}

Our study shows that orally exhaled NO concentrations are increased in asthmatic children compared to healthy controls. In the asthmatic children there was an inverse correlation between orally exhaled NO concentrations and the daily doses of inhaled steroids used. Nasal NO levels, on the other hand, were similar in controls and asthmatics, with or without perennial allergic rhinitis, and did not correlate with doses of inhaled steroids. We also show that nasal NO concentrations are markedly reduced in children with cystic fibrosis, while orally exhaled NO values in these patients did not differ from those found in healthy controls. The same tendency was also seen in the small group of older patients with cystic fibrosis.
Asthmatic bronchial epithelium has been shown to express an inducible NOS which may explain the rise in orally exhaled NO concentrations previously found in adult asthmatics ${ }^{11}$ and also observed in the asthmatic children in this study. The fact that asthmatic children on treatment with higher doses of inhaled glucocorticoids had lower NO concentrations in orally exhaled samples further supports this notion, since the inducible NOS is known to be downregulated by these drugs. ${ }^{9}$

NO concentrations in air sampled from the nose were not significantly different in controls and asthmatics with mild or severe allergic rhinitis. This was somewhat surprising. One would expect expression of iNOS and subsequent production of $\mathrm{NO}$ in inflamed tissue not only in the lower airways but also in the nasal airways in asthmatic patients with rhinitis. However, the major part of the NO normally found in the nasal cavity is not produced in the nasal mucosa but in the paranasal sinuses, as recently described. ${ }^{4}$ An inducible-like highly productive NOS is constitutively expressed in the sinuses, and the formed NO enters the nasal cavity through the sinus ostia. ${ }^{4}$ It is apparent that NO excretion in the paranasal sinuses is not affected in asthmatic children, since nasal NO concentrations did not differ from those seen in controls. Furthermore, treatment with corticosteroids did not seem to influence nasal NO concentrations in asthmatic children. These findings indicate that there is a fundamental difference between the regulation of the iNOS expressed in the lower airways of asthmatics and the regulation of the inducible-like NOS normally found in the mucosa of the paranasal sinuses. Thus sinus NOS is also constitutively expressed in healthy subjects and is not downregulated by glucocorticoid treatment. $^{2417}$

The exchange of air between the sinuses and the nose may theoretically be altered in asthmatics with allergic rhinitis due to swelling of the sinus ostia. This would result in a smaller contribution of NO from the sinuses to the NO found in the nasal cavity. However, this did not seem to occur in the asthmatic children in this study, since nasal NO values were not altered, even in those with severe rhinitis. In patients with cystic fibrosis, however, nasal NO values were markedly decreased compared to controls. In this case, the low nasal NO values might be explained by an impeded passage of NO from the sinuses to the nasal cavity. Thus chronically mucus filled sinuses are the rule rather than the exception in patients with cystic fibrosis. Alternative explanations could be either that the chronic airway inflammation found in cystic fibrosis patients results in damage to NO producing cells in the sinuses and the nasal airway mucosa, or that the altered intracellular milieu found in airway epithelial cells in cystic fibrosis patients affects NOS expression and activity.

Orally exhaled NO values were not altered in cystic fibrosis patients in this study. One might have expected higher NO excretion in the lower airways in these patients, since they suffer from chronic bronchial inflammation which 
would result in increased release of NO in the lower airways, as indeed occurs in asthmatics. However, none of the patients had severe ongoing lower respiratory tract infection at the time of the study. Furthermore, two of the cystic fibrosis patients were treated with inhaled glucocorticoids which are known to inhibit the expression of iNOS in inflamed tissues. Also, the thick and viscous mucus which is characteristic of the inflamed airways in cystic fibrosis may prevent diffusion of NO from the production site in the mucosa to luminal air.

We have earlier suggested a role for NO in airway host defence. ${ }^{4}$ This gas has both bacteriostatic $^{6}$ and antiviral ${ }^{18}$ properties and the concentrations normally found in healthy human paranasal sinuses greatly exceed those that inhibit the growth of, for example, $S$ aureus. ${ }^{6}$ Furthermore, NO may also upregulate ciliary motility. ${ }^{7}$ It is tempting to speculate that the decreased release of NO to the airways of patients with cystic fibrosis and Kartagener's syndrome ${ }^{2}$ further increases their susceptibility to airway infections. It is an intriguing possibility that stimulation of airway NO production might be useful in preventing airway infection in these patients. One possible method of achieving such stimulation has been presented: a recent study shows that nasal NO levels may be increased by administration of L-arginine in vivo. ${ }^{17}$

Measurements of exhaled NO may be used to estimate superficial mucosal NO production in the respiratory tract. Such measurements may be helpful in further understanding the physiological and pathophysiological roles of NO in the airways. Moreover, exhaled NO may be clinically useful in diagnosing and monitoring certain airway diseases. Both an increase and a decrease in airway release of NO may be taken as a marker of disease. However, as shown in this study, it is important to separate the upper from the lower airways in order to detect altered airway NO release at different levels of the respiratory tract. Thus a sample of nasal air may reveal diseases such as cystic fibrosis or Kartagener's syndrome, ${ }^{2}$ whereas orally exhaled NO measurements may be used to diagnose and monitor asthma. ${ }^{1114} 19$ It is likely that the direct nasal sampling method used in this study reflects isolated NO excretion in the nasal airways, whereas samples taken during continuous nasal breathing reflect total NO airway excretion, including secretion by the lower airways. Orally exhaled NO concentrations may be a better reflection of NO release in the lower airways, but contamination from the upper airways-including the nose-may occur even if the subject is breathing only through the mouth. ${ }^{2}$ The high NO excretion in the nasal airways may easily overwhelm changes in lower airway excretion of
NO unless the contribution of nasal NO is minimised. For example, in this study and in an earlier study in adult asthmatics, ${ }^{11}$ there was no significant difference between nasally exhaled NO levels in asthmatics and controls.

We conclude that NO concentrations are increased in orally exhaled air in asthmatic children and are decreased in the nasal airways of children with cystic fibrosis. Measurements of airway NO release in different parts of the airways may be useful in diagnosing and monitoring inflammatory airway diseases such as asthma, Kartagener's syndrome, and cystic fibrosis. These measurements are non-invasive, objective, and very easy to perform, which make them especially suitable in children. This study was supported by grants from the Swedish Medical Research Council (project No 10354), the Swedish Asthma and
Allergy Association, the Swedish Foundation for Health Care Allergy Association, the Swedish Foundation for Health Care Sciences and Allergy Research, the Swedish Heart-Lung Foun-
dation, the Âke Wiberg Foundation, the Magnus Bergvall dation, the Ake Wiberg Foundation, the
Foundation, and the Th C Berg Foundation.

1 Gustafsson LE, Leone AM, Persson MG, Wiklund NP, Moncada S. Endogenous nitric oxide is present in the exhaled air of rabbits, guinea pigs and humans. Biochem exhaled air of rabbits, guinea pigs and

2 Lundberg JON, Weitzberg E, Nordvall SL, Kuylenstierna R, Lundberg JM, Alving K. Primarily nasal origin of exhaled nitric oxide and absence in Kartagener's syndrome. Eur Resp F 1994;7:1501-4.

3 Gerlach H, Rossaint R, Pappert D, Knorr M, Falke KJ. Autoinhalation of nitric oxide after endogenous synthesis in nasopharynx. Lancet 1994;343:518-9.

4 Lundberg JON, Farkas-Szallasi T, Weitzberg E, et al. High nitric oxide production in human paranasal sinuses. Nature Med 1995;1:370-3.

5 Lundberg JON, Rinder J, Weitzberg E, Lundberg JM, Alving K. Nasally exhaled nitric oxide in humans originates mainly in the paranasal sinuses. Acta Physiol Scand mainly in the

6 Mancinelli RL, McKay CP. Effects of nitric oxide and nitrogen dioxide on bacterial growth. Appl Environ Microbiol 1983;46:198-202.

7 Jain B, Rubenstein I, Robbins RA, Leishe KL, Sisson JH. Modulation of airway epithelial cell ciliary beat frequency by nitric oxide. Biochem Biophys Res Commun 1993;191:838.

8 Levison H, Minsdorff CM, Chao J, Turner JAP, Sturgess JM, Stringer DA. Pathophysiology of the ciliary motilit syndromes. Eur f Resp Dis 1983;64(suppl 127):102- 16.

9 Nathan C, Xie Q-W. Nitric oxide synthases: roles, tolls, and

10 Hamid Q, Springall DR, Riveros-Moreno V, et al. Induction of nitric oxide synthase in asthma. Lancet 1993;342:1510

11 Alving K, Weitzberg E, Lundberg JM. Increased amounts of nitric oxide in exhaled air of asthmatics. Eur Resp $\mathcal{F} 1993 ; 6$ $1368-70$

12 Lundberg JON, Hellström PM, Lundberg JM, Alving K. Greatly increased luminal nitric oxide in ulcerative colitis. Lancet 1994 344:1673-4.

13 Lundberg JON, Hellström PM, Lundberg JM, Alving K Nitric oxide in ulcerative colitis. Lancet 1995;345:449.

14 Kharitonov SA, Yates D, Robbins RA, Logan-Sinclair R, Shinebourne EA, Barnes PJ. Increased nitric oxide in exhaled air of asthmatic patients. Lancet 1994;343:133-5.

15 Lundberg JON, Nordvall SL, Weitzberg E, Kollberg H, Alving $\mathrm{K}$. Exhaled nitric oxide in paediatric asthma and cyctic ing K. Exhaled nitric oxide in paediatric as

16 Alving K, Lundberg JON, Nordvall SL. Dose-dependent reduction of exhaled nitric oxide in asthmatic children by inhaled steroids. Am $\mathcal{F}$ Respir Crit Care Med 1995;151: A129.

17 Lundberg JON, Weitzberg E, Rinder J, et al. Calciumindependent nitric oxide synthase activity in human paranasal sinus mucosa: stimulation in vivo by $\mathrm{L}$-arginine.

18 Croen KD. Evidence for an antiviral effect of nitric oxide. $\mathcal{F}$ Clin Invest 1993;91:2446-52.

19 Persson MG, Zetterström O, Agrenius V, Ihre E, Gustafsson LE. Single-breath nitric oxide measurements in asthmatic patients and smokers. Lancet 1994;343:146-7. 